\title{
STUDIES ON INTERSPECIFIC HYBRID IN PHARBITIS. IV. GENETIC ANALYSIS OF PEROXIDASE ISOZYMES IN P. NIL AND P. PURPUREA HYBRID
}

\author{
YOSHIAKI YONEDA
}

Biological Institute, Department of Liberal Arts, Shizuoka University, Shizuoka 422

\section{Received October 18, 1977}

Plant isozymes have been studied from many aspects, for instance, development, differentiation, genetics, etc. (Shannon 1968; Scandalios 1970). As the peroxidase is widely distributed in higher plants in abundant quantities, the isozyme analyses of the enzyme have been conducted in many plants. Peroxidase zymograms in Pharbitis nil were previously described (Yoneda and Endo 1970; Yoneda 1970). Among four strains of $P$. nil, the African strain has a faster moving isozyme $2 \mathrm{C}$, while the other three strains have a slower moving $1 \mathrm{C}$ isozyme on the cathodal side. In a Japanese strain, a null form of the isozyme was found. These isozymes were reported to be controlled by codominant multiple alleles, $P e^{1 \mathrm{C}}, P e^{2 \mathrm{C}}$ and $P e^{\mathrm{O}}$ in a single locus $P e$.

Zymographic studies on interspecific hybrids might possibly lead to understanding the species relationship. In Pharbitis, interspecific hybrids between $P$. nil and $P$. purpurea were recently obtained and their peroxidase isozymes were preliminary reported (Yoneda 1976a). In this study, the cathodal peroxidase isozymes were examined on the hybrids of $P$. nil and $P$. purpurea and their descendants.

\section{MATERIALS AND METHODS}

Materials used were the following strains stocked at the Biological Institute: Pharbitis nil Choisy; W001 (African strain) and Tendan (Chinese strain). P. purpurea Roth; SU1008, SU1031 and SU1033 (solid blue purple flower type) and SU1012 (flaked flower type).

Starch gel electrophoresis was used for the separation of the peroxidase isozymes as previously described by Endo (1968) and Yoneda (1970). Fresh leaves were directly ground in a mortar with a pestle and the exudate was absorbed in a rectangular filter paper, $6 \times 18 \mathrm{~mm}$ or $6 \times 9 \mathrm{~mm}$ of Toyo No. 50 , that was then inserted in the original line of the starch gel. Electrophoresis was run for 4 to $5 \mathrm{~h}$ under constant 200 voltage drop $(10 \mathrm{~V} / \mathrm{cm}$ gel). Benzidine or guaiacol (o-methoxyphenol, McCune 1961) was used for peroxidase staining. Guaiacol was used as follows; $0.5 \mathrm{ml}$ of guaiacol was dissolved in $149 \mathrm{ml}$ of $0.1 \mathrm{M}$ tris acetate buffer, $\mathrm{pH} 4.0$, and $0.5 \mathrm{ml}$ of $30 \%$ hydrogen peroxide was added. This reaction mixture was directly poured to the cut surface of the gel block. 


\section{RESULTS}

\section{Peroxidase isozymes in P. purpurea}

Several peroxidase isozymes were found on the anodal side in P. purpurea. In comparing them to those of $P$. nil (Yoneda and Endo 1970), one characteristic is that the former has a faster moving isozyme beyond the fastest 7A isozyme of the latter. The appearance of the isozyme seems to correspond to the older age of the leaves. On the cathodal side, a sharp isozyme band was found which moved faster than the $2 \mathrm{C}$ isozyme band found in the African strain of $P$. nil. $P$. purpurea-specific cathodal isozyme was designated as $3 \mathrm{C}$. The $3 \mathrm{C}$ isozyme appears in the leaf, stem and other parts almost irrespective of age. The present study is mainly concerned with this isozyme band.

\section{Peroxidase isozymes in P. nil $\times$ P. purpurea hybrids}

Since 1975, eight interspecific hybrids of the African strain of $P$. nil $\times P$. purpurea, abbreviated to AP, were obtained, among which the morphological character of six hybrids, AP17, 27, 31, 36, 39 and 40, were already described (Yoneda 1976a). The character of the other two hybrids, AP54 and 55, is as follows; AP54 has blue flaked flower and three lobed leaf, derived from crossing of the African strain of $P$. nil with SU1012 of P. purpurea, and AP55 has blue solid flower and three lobed leaf, which was obtained from crossing of the same female plant with SU1031 (intense purple solid flower) of. P. purpurea.

All eight hybrids were found to have both $2 \mathrm{C}$ and $3 \mathrm{C}$ isozymes, as shown in Fig. 1d. Each isozyme band is assumed to be derived from the parents, namely, $2 \mathrm{C}$ from the African strain of $P$. nil (Yoneda, 1970) and 3C from P. purpurea (Fig. 1c).

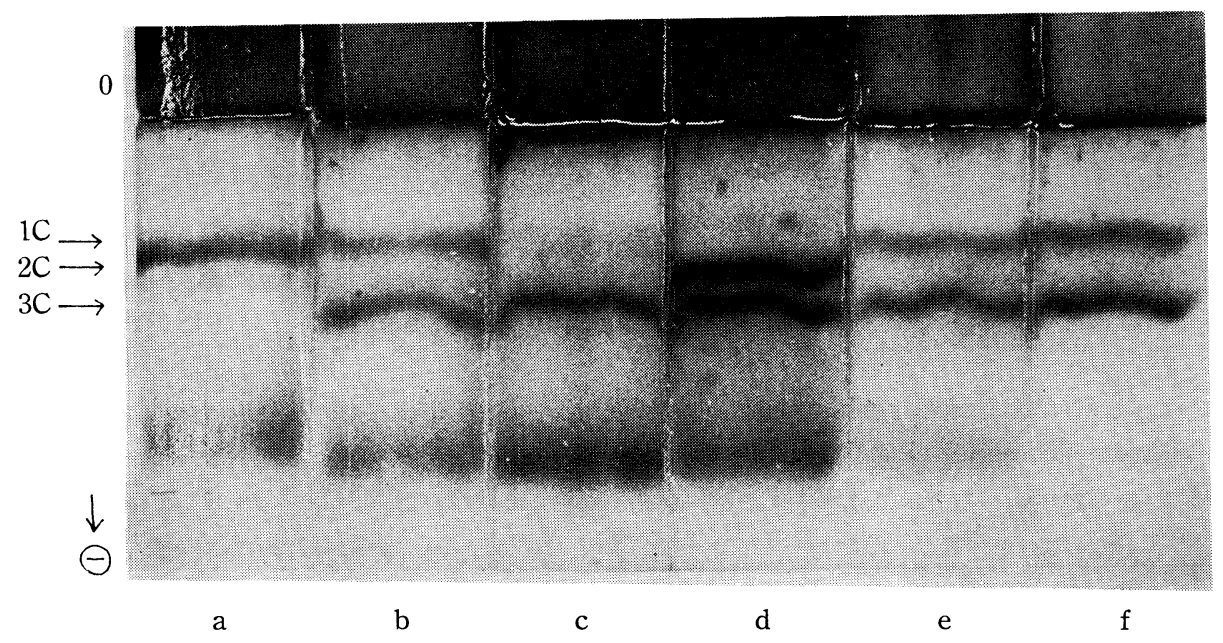

Fig. 1. Leaf peroxidase zymograms in Pharbitis. 0 denotes the origin.

a) 1C type, Chinese Tendan strain of $P$. nil.

b, e, f) 1C-3C type, interspecefic hybrid of $P$. purpurea $\times$ Chinese Tendan strain of $P$. nil.

c) 3C type, $P$. purpurea.

d) 2C-3C type, interspecific hybrid of the African strain of $P$. nil $\times P$. purpurea. 
Table 1. $\mathrm{F}_{2}$ segregation of peroxidase isozyme and leaf shape in interspecific hybrid of the African strain of $P$. nil $\times P$. purpurea

\begin{tabular}{|c|c|c|c|c|c|c|c|}
\hline \multirow{2}{*}{$\begin{array}{c}\mathrm{F}_{1} \\
(2 \mathrm{C}-3 \mathrm{C} \\
\text { three-lobed })\end{array}$} & \multicolumn{2}{|c|}{$2 \mathrm{C}$} & \multicolumn{2}{|c|}{$2 \mathrm{C}-3 \mathrm{C}$} & \multicolumn{2}{|c|}{$3 \mathrm{C}$} & \multirow{2}{*}{ Total } \\
\hline & three-lobed & cordate & three-lobed & cordate & three-lobed & cordate & \\
\hline AP27 & 11 & 2 & 21 & 7 & 2 & 10 & 53 \\
\hline AP31 & 16 & 2 & 14 & 3 & 4 & 9 & 48 \\
\hline AP39 & 10 & 0 & 18 & 4 & 5 & 9 & 46 \\
\hline $\mathrm{AP} 40$ & 6 & 0 & 12 & 2 & 3 & 2 & 25 \\
\hline \multirow{2}{*}{ Total } & 43 & 4 & 65 & 16 & 14 & 30 & \multirow{2}{*}{172} \\
\hline & & & \multicolumn{2}{|c|}{81} & \multicolumn{2}{|c|}{44} & \\
\hline
\end{tabular}

Table 2. Abnormal $\mathrm{F}_{2}$ segregation of peroxidase isozyme and leaf shape in interspecific hybrid of the African strain of $P$. nil $\times P$. purpurea

\begin{tabular}{cccccccc}
\hline & \multicolumn{2}{c}{$2 \mathrm{C}$} & \multicolumn{2}{c}{$2 \mathrm{C}-3 \mathrm{C}$} & \multicolumn{2}{c}{$3 \mathrm{C}$} & Total \\
$\begin{array}{c}\mathrm{F}_{1} \mathrm{C}-3 \mathrm{C}, \\
\text { three-lobed })\end{array}$ & three-lobed & cordate & three-lobed & cordate & three-lobed & cordate & \\
\hline AP17 & 38 & 0 & 8 & 0 & 0 & 0 & 46
\end{tabular}

Another kind of interspecific hybrids, PC $(P$. purpurea $\times$ Chinese Tendan strain of $P$. nil) were obtained (Yoneda 1976b). They have also two isozyme bands, but they are $1 \mathrm{C}$ and $3 \mathrm{C}$ (Fig. 1b, e, f); the former seems to be derived from Tendan strain of $P$. nil (Fig. 1a) and the latter from P. purpurea (Fig. 1c).

\section{3. $F_{2}$ segregation of the peroxidase isozyme types}

Among eight AP hybrids, AP55 was completely sterile, AP54 produced only 4 seeds and AP36 had 7 seeds. Another five hybrids produced about 20 to 50 seeds, so these were immediately sown and $\mathrm{F}_{2}$ segregation of the isozyme types was studied. The results were summarized in Table 1 . AP27, 31, 39 and 40 segregated three types concerned with the isozyme, namely, 47 plants of $2 \mathrm{C}$ type, 81 of $2 \mathrm{C}-3 \mathrm{C}$ and 44 of $3 \mathrm{C}$. The segregration ratio fits well to $12 \mathrm{C}: 22 \mathrm{C}-3 \mathrm{C}: 13 \mathrm{C}\left(\chi^{2}=0.442,0.95>\mathrm{P}>0.80\right)$, although AP31 had a somewhat lower number of $2 \mathrm{C}-3 \mathrm{C}$ type. This result indicates that the gene $P e^{3 C}$ specifying $3 \mathrm{C}$ isozyme is a codominant allele to the $P e^{2 C}$ gene. Table 1 also indicates that three-lobed leaf shape and cordate leaf shape segregated 122 and 50 plants, respectively in $F_{2}$, that fits to a $3: 1$ ratio $\left(\chi^{2}=1.520,0.50>P>0.20\right)$. The result suggests a linked inheritance of $3 \mathrm{C}$ isozyme and cordate leaf shape in $\mathrm{AP}$ hybrids.

As shown in Table 2, AP17 showed abnormal $\mathrm{F}_{2}$ segregation, namely, no $3 \mathrm{C}$ type, but many $2 \mathrm{C}$ and a few $2 \mathrm{C}-3 \mathrm{C}$ type were found. Such an aberrant segregation may be the case in AP36; namely, 6 plants have $2 \mathrm{C}$ type and the one is $2 \mathrm{C}-3 \mathrm{C}$ type.

$\mathrm{PC}$ hybrids are also very low in seed fertility. One of them segregated three types of the isozyme; namely, $1 \mathrm{C}, 1 \mathrm{C}-3 \mathrm{C}$ and $3 \mathrm{C}$ types were found in the individual number of 3,9 and 3 , respectively. 


\section{Backcross of AP hybrid}

To investigate the segregation of the isozyme types in AP hybrid, backcrosses of AP hybrids were tried. Although about half number of the pollens in AP17 hybrid was normal in size, ca. $120 \mu$ in pollen diameter, all crossings using AP17 as pollen parent failed. In contrast, AP17 was able to be backcrossed when used as a female plant. When AP17 hybrid (2C-3C type) was crossed with the African strain (2C type) of $P$. nil, 18 seeds were harvested and sown immediately. Among them, 15 plants were $2 \mathrm{C}$ type and the remaining 3 were $2 \mathrm{C}-3 \mathrm{C}$ type. Thus, abnormal segregation of the isozyme genes in the megasporogenesis was assumed to be one cause of aberrant segregation in $F_{2}$, although we have not yet any available observations about microsporogenesis. All the crossings of AP17 (우) with P. purpurea ( $\hat{\delta}$ ) ended in failure.

AP27 (2C-3C type) was crossed with the African strain of $P$. nil, resulting in 17 seeds. They were cultivated and examined for the isozyme type, where 9 plants were $2 \mathrm{C}$ and 8 were $2 \mathrm{C}-3 \mathrm{C}$ type. Moreover, AP27 was able to be relatively easily pollinated and fertilized with $P$. purpurea ( $3 \mathrm{C}$ type). Among 8 backcrossed segregants, 4 plants were $2 \mathrm{C}-3 \mathrm{C}$ type, and the other 4 were $3 \mathrm{C}$ type. This suggests that the segregation of $P e^{2 C}$ and $P e^{3 C}$ genes in AP27 is normal.

\section{DISCUSSION}

In many plants, one isozyme, specific for a strain or a species, was specified by a single gene and when hybridized, only two isozyme bands, derived from each parent, appear without formation of hybrid enzyme (Wall 1968; Hamil and Brewbaker 1969). Such isozymes are assumed to be monomeric in nature. The genetic behaviour of the cathodal peroxidase isozyme in Pharbitis seems to belong to this group (Fig. 2). In the genus Pharbitis, $P$. nil has $1 \mathrm{C}$ type in the Japanese strain (including null form), the Nepalese as well as Chinese Tendan strain, and 2C type in the African strain (Yoneda 1970). $P$. hederacea is 2C type (Yoneda, in press). In the present study, $P$. purpurea is shown to be $3 \mathrm{C}$ type.

The interspecific hybrid between a Japanese and an African strain of $P$. nil (TA) showed $1 \mathrm{C}-2 \mathrm{C}$ type. The interspecific hybrid between $P$. hederacea and Tendan strain of $P$. nil $(\mathrm{HC})$ showed also $1 \mathrm{C}-2 \mathrm{C}$ type. In the present study, $2 \mathrm{C}-3 \mathrm{C}$ isozyme type was found in the interspecific hybrid of the African strain of $P$. nil and $P$. purpurea (AP) and $1 \mathrm{C}-3 \mathrm{C}$ type was in the hybrid of $P$. purpurea $\times$ Tendan strain of $P$. nil (PC).

In $\mathrm{F}_{2}, 1 \mathrm{C}, 1 \mathrm{C}-2 \mathrm{C}, 2 \mathrm{C}$ or $2 \mathrm{C}, 2 \mathrm{C}-3 \mathrm{C}, 3 \mathrm{C}$ types segregated at the ratio of $1: 2: 1$ in TA, HC or AP hybrids except in AP17.

$P$. congesta has a cathodal peroxidase isozyme which corresponds to $1 \mathrm{C}$ in electrophoretic mobility. Its genetic behaviour, however, is not clear, because of the failure in interspecific crossing with three other species.

Representation of the cathodal peroxidase zymograms in Pharbitis was summarized in Fig. 2. Noteworthy is that $P$. hederacea, the so-called American morning glory, has the same $2 \mathrm{C}$ peroxidase isozyme with the African strain of $P$. nil and they are almost freely crossed when the former is used as female parent.

As mentioned above, aberrant segregation was recognized in $F_{2}$ of AP17 hybrid. 


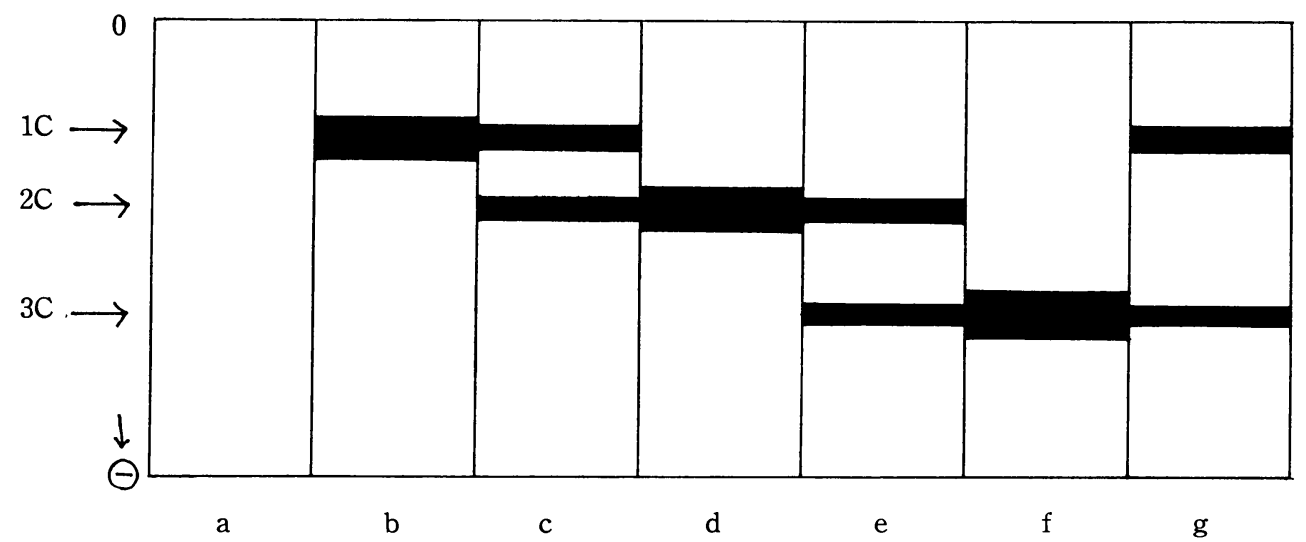

Fig. 2. Schematic representation of the cathodal peroxidase isozyme types in Pharbitis. 0 denotes the origin.

a) null form, $P$. nil, TO36.

b) 1C type, $P$. nil, TO16 and other Japanese strains, Nepalese and Chinese Tendan; $P$. congesta.

c) 1C-2C type, $P$. hederacea $\times P$. nil, Tendan hybrid; $P$. nil, TO16 $\times$ Africa hybrid.

d) 2C type, $P$. nil, Africa; $P$. hederacea.

e) 2C-3C type, $P$. nil, Africa $\times P$. purpurea hybrid.

f) 3C type, $P$. purpurea.

g) 1C-3C type, $P$. purpurea $\times P$. nil. Tendan hybrid.

One parent, the African strain of $P$. nil, has sky blue flower and three-lobed leaf and the other parent, SU1012 of $P$. purpurea, has blue purple flaked flower and cordate leaf. The hybrid has flowers with blue flakes in light blue ground color, three-lobed leaf and $2 \mathrm{C}-3 \mathrm{C}$ peroxidase isozyme type. All $\mathrm{F}_{2}$ plants examined have sky blue solid flowers and three-lobed leaves. Many plants were $2 \mathrm{C}$ type and a few were $2 \mathrm{C}-3 \mathrm{C}$ type as shown in Table 2. Thus, the cordate leaf type, $3 \mathrm{C}$ isozyme type and flaked characters were completely eliminated in $\mathrm{F}_{2}$. The present results indicate that abnormal assortment of $P e^{2 C}$ and $P e^{3 C}$ genes seems to occur through the female gametes, which would be a cause of aberrant segregation in $\mathrm{F}_{2}$ of AP17 hybrid. Studying on the reciprocal backcrosses in the interspecific hybrid of Phaseolus vulgaris $\times P$. coccineus, Wall (1968) found a differential elimination of a leucine aminopeptidase allele through male gamete of the hybrid and suggested the existence of differences between the genomes of the species. Such aberrant segregation was recognized only in AP17 hybrid. Further studies on this line are under way.

\section{SUMMARY}

The interspecific hybrids between Pharbitis nil Choisy and $P$. purpurea Roth were very low in fertility or completely sterile. $\mathrm{F}_{2}$ segregations were studied on the cathodal peroxidase isozymes. $P$. purpurea has $3 \mathrm{C}$ isozyme and $P$. nil has $2 \mathrm{C}$ (Africa) and $1 \mathrm{C}$ (Tendan and others). The gene $P e^{3 C}$ specifying $3 \mathrm{C}$ isozyme is a codominant allele with $P e^{2 C}$ and $P e^{1 C(0)}$. 


\section{ACKNOWLEDGMENTS}

The author is indebted to Miss Yoshiko Ishida for her technical assistance and to Mr. Shigeichi Tamaki for his help in cultivation of the morning glory. The author is also grateful to Mr. John De Young for his reading the manuscript.

\section{REFERENCES}

Endo, T., 1968 Indoleacetate oxidase activity of horseradish and other plant peroxidases. Plant and Cell Physiol. 9: 333-341.

Hamil, D. E., and J. L. Brewbaker, 1969 Isoenzyme polymorphism in flowering plants. IV. The peroxidase isoenzymes of maize (Zea mays). Physiol. Plant. 22: 945-958.

McCune, D. C., 1961 Multiple peroxidases in corn. Ann. N. Y. Acad. Sci. 94: 723-73n.

Scandalios, J. G., 1974 Isozymes in development and differentiation. Ann. Rev. Plant Physiol. 25: $225-258$.

Shannon, L. M., 1968 Plant isozymes. Ann. Rev. Plant Physiol. 19: 187-210.

Wall, J. R., 1968 Leucine aminopeptidase polymorphism in Phaseolus and differential elimination of the donor parent genotype in interspecific backcrosses. Biochem. Genet. 2: 109-118.

Yoneda, Y., 1970 Peroxidase isozymes in four strains of morning glory. Japan. J. Genetics 45: 183-188.

Yoneda, Y., 1976a Studies on interspecific hybrid in Pharbitis. I. Morphological observation on a hybrid of Pharbitis nil $\times$ Pharbitis purpurea. Rep. Dept. Lib. Arts, Shizuoka Univ. (Sciences) 12: $27-34$.

Yoneda, Y., 1976b Interspecific hybrids between Pharbitis nil and Pharbitis purpurea. (Abstract, in Japanese) Japan. J. Genetics 51: 450.

Yoneda, Y., Studies on interspecific hybrid in Pharbitis. III. Genetic analyses of leaf shapes and peroxidase isozymes in $P$. hederacea $\times P$. nil hybrids. Rep. Dept. Lib. Arts, Shizuoka Univ. (Sciences) 13, in press.

Yoneda, Y., and T. Endo, 1970 Peroxidase isozymes and their indoleacetate oxidase activity in the Japanese morning glory, Pharbitis nil. Plant and Cell Physiol. 11: 503-506. 